\title{
The challenge of COVID-19 low disease prevalence for artificial intelligence models: report of 1,610 patients
}

\author{
Carlo C. Quattrocchi ${ }^{1 \wedge}$, Carlo A. Mallio ${ }^{1 \wedge}$, Gabriele Presti ${ }^{1}$, Bruno Beomonte Zobel ${ }^{1}$, Jacopo Cardinale $^{2}$, \\ Mario Iozzino ${ }^{3}$, Sabino W. Della Sala ${ }^{2}$ \\ ${ }^{1}$ Departmental Faculty of Medicine and Surgery, Unit of Diagnostic Imaging and Interventional Radiology, Università Campus Bio-Medico di \\ Roma, Rome, Italy; ${ }^{2}$ Division of Diagnostic Radiology, Rovereto Hospital, Azienda Provinciale per i Servizi Sanitari, Trento, Italy; ${ }^{3}$ Department of \\ Interventional Radiology, "S. Maria Goretti” Hospital, Latina, Italy
}

Correspondence to: Carlo A. Mallio, MD. Departmental Faculty of Medicine and Surgery, Unit of Diagnostic Imaging and Interventional Radiology, Università Campus Bio-Medico di Roma, Via Alvaro del Portillo, 21, 00128 Rome, Italy. Email: c.mallio@unicampus.it.

Submitted Jun 20, 2020. Accepted for publication Jul 02, 2020.

doi: 10.21037/qims-20-782

View this article at: http://dx.doi.org/10.21037/qims-20-782

\section{Introduction}

It has been shown that artificial intelligence (AI) may yield rapid and improved detection of coronavirus disease 2019 (COVID-19) by integrating chest CT findings with clinical symptoms, exposure history and laboratory testing (1).

Early detection and reduction of workload for healthcare workers have been proposed as main applications of $\mathrm{AI}$ in COVID-19 pandemic (2), despite limitations, constraints and pitfalls $(3,4)$.

\section{Methods}

In Italy, the first western country to be hit by the COVID-19 pandemic, our institution implemented a multi-site collaborative effort aimed to centralize the reading of chest $\mathrm{CT}$ scans using an AI solution (InferRead ${ }^{\mathrm{TM}}$ CT Lung, Infervision, DE, USA) as a rapid diagnostic tool to: (I) label patients with suspected COVID-19 infection, (II) alert the radiologists for images review and, eventually, (III) prioritize the final report of suspected cases and RT-PCR tests for the definite diagnosis. Institutional Review Board (IRB) approval was obtained for this study.

The core algorithm applied in this study was based on a deep convolutional neural network structure. The algorithm includes automatic segmentation of COVID-19 lung lesions and its quantitative output also provides a risk probability for the diagnosis of COVID-19 pneumonia.

During the whole timeframe, we a priori defined a risk of $30 \%$ as cut-off value to stratify the AI probability of COVID-19 into "Low Risk" (<30\%) and "High Risk" $(\geq 30 \%)$. Indeed, a preliminary study conducted in our hospital on the first 100 patients showed that, among the suspected cases identified by AI, patients with COVID-19 probability $<30 \%$ received a confirmed diagnosis by RTPCR with a low percentage of $4.8 \%$.

\section{Results}

Between February $17^{\text {th }}$ and May $24^{\text {th }} 2020$, the AI dedicated server received and consecutively assessed 1,610 chest CT scans. Of these, $37.8 \%(608 / 1,610)$ were labeled as suspected COVID-19 cases by AI, reaching the zenith of

${ }^{\wedge}$ Carlo C. Quattrocchi, ORCID: 0000-0001-6823-7707; Carlo A. Mallio, ORCID: 0000-0002-0149-0801; Bruno Beomonte Zobel, ORCID: 0000-0001-9227-5535 


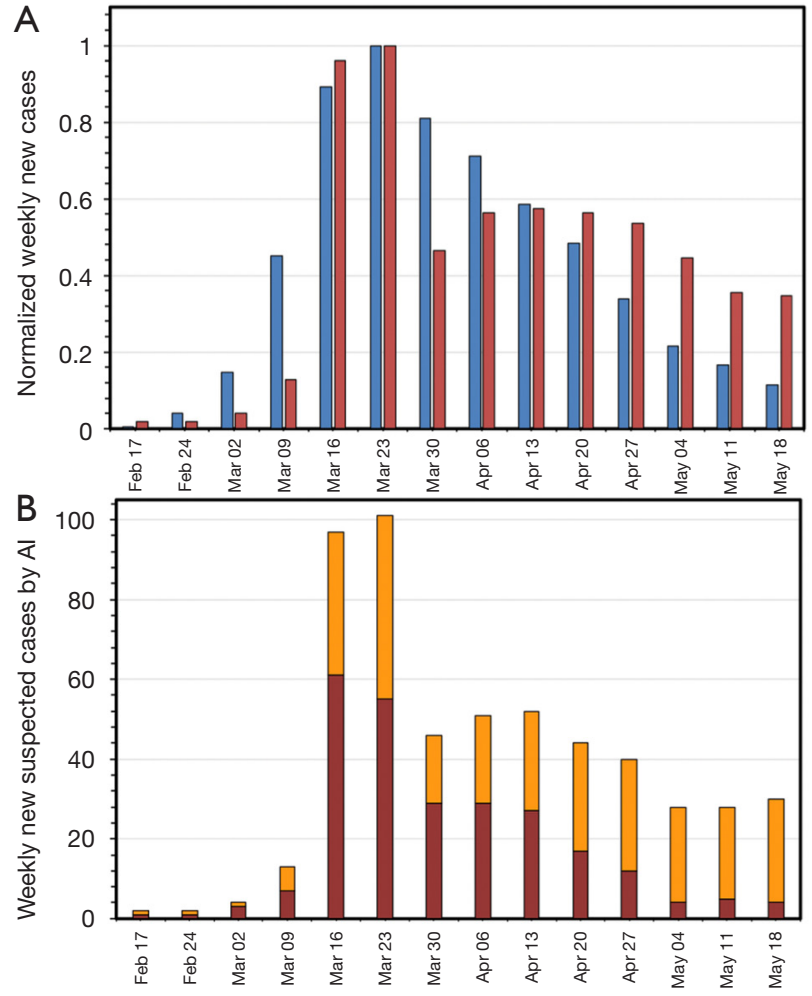

Figure 1 Weekly new suspected cases identified by AI between February $17^{\text {th }}$ and May $24^{\text {th }}$ in Italy. (A) Comparison of weekly new suspected cases identified by AI (red bars) with national data (blue bars). Data are normalized to the number at the zenith for both distributions (number of cases at the zenith is 38,551 for national data and 101 for $\mathrm{AI}$ server data); (B) risk stratification of the number of weekly new suspected cases identified by AI into "High Risk" (red bars) and "Low Risk" (orange bars). AI, artificial intelligence.

new cases in the week of March $23^{\text {rd }}-29^{\text {th }}$. Noteworthy, despite inter-regional differences, the prevalence of new cases in the AI database mirrored what was observed at national level as registered by the Istituto Superiore di Sanità (the zenith of daily new cases of COVID-19 in Italy was on March 23 $3^{\text {rd }}$ ) (5) (Figure 1A). During the following weeks, despite a decreased prevalence of COVID-19 in Italy (down to $11 \%$ of the number of cases at the zenith on May $\left.24^{\text {th }}\right)$, the number of suspected cases identified by AI remained relatively high ( $41 \%$ of the number of cases at the zenith in the population assessed by AI).

The risk stratification of suspected cases into "High Risk" and "Low Risk" showed that, despite the number of patients with "High Risk" scores dropped during the month of May, the number of patients labeled as "Low Risk" was high and, with the decreased prevalence of the disease, represented the majority of suspected cases identified by AI (Figure 1B).

\section{Comment}

The AI model applied in this study was based on chest CT data and did not integrate clinical symptoms, exposure history or laboratory testing. Nevertheless, our findings support AI as a tool to label suspected patients with COVID-19 infection on chest CT scans and prioritize management. Also, our results highlight the disease prevalence as the main challenge for AI solutions. As Mei et al. (1) pointed out, the implementation of AI trained with either chest CT datasets only or integrating epidemiological, clinical, laboratory with radiological information, shows high diagnostic performance where and when the prevalence of disease is high. However, it is unlikely to perform just as well where and when the prevalence of disease is low.

Although our arguments require further investigations, the analysis on an Italian testing dataset proves that AI predicting models for COVID-19 can be applied for binary classification in the high prevalence settings but should take into account risk stratification in low prevalence settings, in order to improve the diagnostic performance and decrease the false positive rates in the detection of COVID-19.

\section{Acknowledgments}

Funding: None.

\section{Footnote}

Conflicts of Interest: All authors have completed the ICMJE uniform disclosure form (available at http://dx.doi. org/10.21037/qims-20-782). The authors have no conflicts of interest to declare.

Open Access Statement: This is an Open Access article distributed in accordance with the Creative Commons Attribution-NonCommercial-NoDerivs 4.0 International License (CC BY-NC-ND 4.0), which permits the noncommercial replication and distribution of the article with the strict proviso that no changes or edits are made and the original work is properly cited (including links to both the formal publication through the relevant DOI and the license). See: https://creativecommons.org/licenses/by-nc-nd/4.0/. 


\section{References}

1. Mei X, Lee HC, Diao KY, Huang M, Lin B, Liu C, Xie Z, Ma Y, Robson PM, Chung M, Bernheim A, Mani V, Calcagno C, Li K, Li S, Shan H, Lv J, Zhao T, Xia J, Long Q, Steinberger S, Jacobi A, Deyer T, Luksza M, Liu F, Little BP, Fayad ZA, Yang Y. Artificial intelligence-enabled rapid diagnosis of patients with COVID-19. Nat Med 2020. [Epub ahead of print]. doi:10.1038/s41591-0200931-3.

2. Vaishya R, Javaid M, Khan IH, Haleem A. Artificial Intelligence (AI) applications for COVID-19 pandemic.

Cite this article as: Quattrocchi CC, Mallio CA, Presti G, Beomonte Zobel B, Cardinale J, Iozzino M, Della Sala SW. The challenge of COVID-19 low disease prevalence for artificial intelligence models: report of 1,610 patients. Quant Imaging Med Surg 2020;10(9):1891-1893. doi: 10.21037/qims-20-782
Diabetes Metab Syndr 2020;14:337-9.

3. Naudé W. Artificial intelligence vs COVID-19: limitations, constraints and pitfalls. AI Soc 2020. [Epub ahead of print]. doi:10.1007/s00146-020-00978-0.

4. Neri E, Miele V, Coppola F, Grassi R. Use of CT and artificial intelligence in suspected or COVID-19 positive patients: statement of the Italian Society of Medical and Interventional Radiology. Radiol Med 2020;125:505-8.

5. Istituto Superiore di Sanità. Bollettino-sorveglianzaintegrata-COVID-19. 2020. Available online: https:// www.epicentro.iss.it/coronavirus/ (Accessed on May 25th, 2020). 